\title{
Lélia ou a arte de viver
}

\section{Lélia or the art of living}

Renata Soares Junqueira

Universidade Estadual Paulista "Júlio de Mesquita Filho", Araraquara, São Paulo, São Paulo / Brasil

Bolsista do $\mathrm{CNPq}$

renata@fclar.unesp.br

Resumo: Apresenta-se aqui um breve exercício de crítica sobre o livro que a poetisa-pintora Lélia Parreira Duarte publicou em 2009: Exercícios de viver em palavra e cor.

Palavras-chave: poesia, pintura, exercícios de viver, Lélia Parreira Duarte.

Abstract: Here is a brief exercise of criticism about the book that the poetess-painter Lélia Parreira Duarte published in 2009: Exercises of living in word and color.

Keywords: poetry, painting, exercises of living, Lélia Parreira Duarte.

Recebido em 3 de agosto de 2016 Aprovado em 27 de agosto de 2016

Não sei ao certo, mas suponho que tenha sido no término do primeiro semestre letivo de 2011 que Lélia se afastou da docência universitária. Digo isto porque o currículo de Lélia Maria Parreira Duarte na Plataforma Lattes do Conselho Nacional de Desenvolvimento Científico e Tecnológico (CNPq) teve a sua última atualização a 20 
de abril de 2011. E é sabido que de 3 a 5 de maio do mesmo ano ela participava, em Lisboa, do Colóquio Internacional "Nietzsche, Pessoa, Freud", evento cuja divulgação, aliás, foi feita com um cartaz que era uma das várias pinturas de Lélia motivadas pelo poeta português das múltiplas faces: "Fernando Pessoa e seus heterônimos". O ensaio ilustrado que a professora/artista publicou em 2011 - Potência e negatividade em Fernando Pessoa - e que teve lançamento também em Portugal, precisamente em maio, no mesmo Colóquio que acabo de referir, já não consta no seu currículo Lattes... Isto significa que a Professora Lélia, quando regressou de Lisboa em maio de 2011, já se ia desprendendo do ofício universitário para se dedicar livremente às atividades artísticas que são a sua paixão de hoje: pintar e poetar.

Nesta festiva ocasião de justa homenagem a Lélia Parreira Duarte, gostaria eu de tecer alguns despretensiosos comentários sobre o seu primeiro livro de ficção dobrada, combinando poesia e pintura. Exercícios de viver em palavra e cor, volume publicado em 2009 pela editora Veredas \& Cenários, de Belo Horizonte - no âmbito da coleção Obras em Dobras/ Poiesis interlinguagens -, é com efeito uma pequena pérola cintilante. $\mathrm{O}$ bom gosto que se evidencia no trabalho editorial é já um convite ao prazer visual: combinados com o vermelho da quarta capa, o azul e o amarelo da capa do livro anunciam a álacre profusão de cores vivas com que o leitor se deparará ao folhear o volume, não só quando olhar para cada uma das vinte e quatro pinturas que os poemas ali reunidos comentam, mas também quando reparar no fundo colorido das folhas de papel nobre que acolhem os poemas como se fossem óvulos de flores campestres. De fato, o livrinho parece um jardim prenhe de frutos paradisíacos que a poetisa/pintora sorrateiramente oferece ao seu leitor - à mineira, como quem não quer nada que não seja saciar, generosamente, o apetite de um companheiro de jornada -, sem contudo dissimular de todo um enigmático riso de Mona Lisa que, de resto, era mesmo de esperar de alguém como Lélia, que durante muitos anos se esmerou, como pesquisadora e crítica literária, no estudo da ironia na literatura. Não se iluda, pois, o leitor precavido com a aparente singeleza destes cantos inaugurais da nossa homenageada. São cantos de sereia, como adverte um dos poemas (cf. p. 46) e também, logo na capa do volume, a tela "Madrugada" (de 2000), que nos confronta com uma auroral (iniciática?) dança de serpentes que ameaçam enredar-nos ao pé de um... abismo! Quem a conhece minimamente sabe disto: Lélia não dá ponto sem nó. Mas prossigamos com a descrição do livro. 
Na quarta capa, sobre fundo vermelho, lemos projeções facsimilares de pequenos fragmentos críticos que saúdam a poetisa/pintora, assinados por Ângela Vaz Leão, Helder Macedo e Teresa Cristina Cerdeira. Nas abas da capa uma foto da pintora acompanhada de uma breve apresentação do seu mestre de pintura, Carlos Buere. Antes do competente prefácio de Maria Theresa Abelha Alves um pequeno poema introdutório que tem o mérito de sintetizar o que há de essencial neste livro de Lélia, experiente leitora e mestra que com sábia humildade se apresenta como aprendiz dos sentidos da vida em palavras e em cores:

$$
\begin{array}{r}
\text { Com o estudo da ironia } \\
\text { e do humor } \\
\text { e o manuseio de } \\
\text { palavras, } \\
\text { tintas e pincéis, } \\
\text { tento aprender } \\
\text { a fragilidade do sentido } \\
\text { e a importância } \\
\text { do intervalo } \\
\text { e da cumplicidade }
\end{array}
$$

Recomendo o exercício! (p. 9)

Além deste, outros dois poemas escritos (quase pintados!) sobre lápides em que se alternam o fundo amarelo e o branco revelam também a mesma humildade da mestra/aprendiz. São eles o de abertura da coletânea - Sempre / é melhor / pintar / que não pintar... - e o que a encerra - "Tentar sempre" -, ambos escritos em 2008 e eleitos pela autora como portais desta obra em que se perscruta "O enigma do ser / e do desejo" (p. 38), sabendo-se todavia de antemão que ele só se poderá encontrar num "entrelugar" (p. 44) cuja via de acesso passa certamente por uma série de tentativas de aproximação de opostos como vida e morte, início e fim, sonho e realidade, águas tranquilas e tempestades, luz e sombra, tudo e nada, falar e calar, verdes bradando aos céus "Onde está o amarelo?" (p. 60) etc.

Mas ainda antes do pórtico amarelo podemos ler o prefácio, que ilumina com penetrantes focos de luz os mais surpreendentes meandros destes exercícios de Lélia, seja no seu diálogo com outros pintores (Chagall, Kandinsky, Monet, Van Gogh) e com outros poetas (Drummond, 
Fernando Pessoa e heterônimos), ${ }^{1}$ seja na delicada mas persistente ironia com que textos e telas insinuam sempre, acima de tudo, "O desejo de arte" (p. 38). São certeiras as notações de Theresa Abelha, que vê a pintora-aprendiz um tanto dividida ainda entre os influxos de Chagall, Kandinsky, Van Gogh ("implícita presença a habitar as telas pela sedução do amarelo e dos girassóis", p. 12) e Monet. Ou, poderíamos dizer de outro modo, entre as cores fortes de um expressionismo abrasileirado pelo predomínio do verde, do amarelo e do azul, e de outro lado os traços diluídos, os borrões e sombras de um impressionismo fantasmático mas também singularizado pela recorrência do rosa, do lilás e do branco. Sobre estas duas tendências da pintura inicial de Lélia (a coletânea reúne telas que são, na sua maioria, datadas de 1999) ${ }^{2}$ é que eu gostaria de tentar aqui algumas incipientes reflexões.

Ainda que as telas inaugurais do livro (quer a "Madrugada", que aparece logo na capa para depois reaparecer à p. 31, quer o esplêndido "Cores e sonhos I", à p. 21, quer ainda "Instantânea eternidade", à p. 23) sejam precisamente as de cores mais gritantes, sou de opinião de que nesta coletânea a pintora revela, talvez subconscientemente, predileção pelo impressionismo da pintura de Monet e da música de Debussy convocados, ambos, para o corpo do poema "Deslizando" (p. 36), que comenta a tela homônima (p. 37): "Flores / fluindo / no fluxo / do azul. (...)." Se não, note-se a musicalidade dos poemas - a repetição dos sons de "f" e de "u" na primeira parte de "Deslizando", por exemplo:

\footnotetext{
${ }^{1}$ Indico, como sugestão, a probabilidade de uma interlocução (talvez mais discreta) dos poemas e telas de Lélia com a poesia de duas grandes autoras portuguesas do século XX: Florbela Espanca e Sophia de Mello Breyner Andresen, em cujas obras são também recorrentes, respectivamente, imagens de flores e do mar. Compare-se, por exemplo, o poema "Madrugada" (p. 30), de Lélia, que termina com "Abismo / em que / me perco,/ me achando.", com o conhecido soneto florbeliano de Charneca em flor, "Amar!", que tem por desfecho "Que seja a minha noite uma alvorada, / Que me saiba perder... pra me encontrar...". Também com pintores portugueses, aliás, há evidências de interlocução nas telas de Lélia. Especialmente no que concerne ao seu interesse pictórico por Fernando Pessoa e os heterônimos, sugiro uma comparação com telas de Júlio Pomar e Miguel Yeco.

${ }^{2}$ Lélia começou a pintar em 1994, como se lê numa das seções do seu portfolio, disponível em: <http://www.leliaparreira.com.br/index.php>.
} 
Flores

fluindo

no fluxo

do azul.

Ao fundo,

Debussy,

"La plus que lente"

(...) (p. 36)

Em forma e conteúdo o poema lembra a Chanson d'automne de Verlaine, com versos curtos em estrofes que no poeta francês sugeriam o movimento outonal da folha caindo de uma árvore. Mera coincidência? Parece-me que não. Os poemas-canções de Lélia acompanham telas que, do princípio ao fim da coletânea, se vão suavizando em traços e cores, diluindo-se - talvez para sugerir a falácia das aparências e um anseio de captação da alma das coisas, ou de flagrar as formas em movimento, em permanente devir. E não será essa procura obstinada da mais autêntica face das coisas o que está por trás do especial interesse da pintora (que sempre foi professora de literatura portuguesa, convém não esquecer) pelas várias faces de Fernando Pessoa? Se na tela "Para Ricardo Reis" as miríades de flores vermelhas e cor-de-rosa parecem voláteis borboletas querendo desprender-se da terra, no quadro "Chuva oblíqua" uns restos de luz crepuscular combinam-se com sombras (borrões, reflexos de imagens no espelho d'água do mar) para deixar ver apenas "vultos" (p. 44). E os pincéis cantam para sugerir que também pode haver música na própria pintura que os versos vêm ilustrar.

Seguindo na mesma linha de interpretação - e já para finalizar esta pequenina e muito modesta homenagem à querida Lélia - gostaria de propor uma leitura das três figuras da tela "Enigmas" (p. 63) como sombras tênues, coloridas e travestidas, dos três grandes heterônimos de Pessoa... ou seriam antes as três enigmáticas veladoras do seu drama estático $O$ marinheiro? Não por acaso, o poemeto "Enigmas" divide a página branca (p. 62), que antecede a da pintura homônima, com o poema "Eurídice". Alusão a Orpheu e convite a uma descida abissal ao Hades? Mais uma referência à música? Quiçá? As formas singelas desta poetisa-pintora estão, como ela mesma o diz, entranhadamente ligadas ao verbo tentar - mas, já agora, é preciso ler este verbo nos seus dois 
sentidos: o de tentativa e o de tentação. Ou não estaríamos falando de Lélia Parreira Duarte.

Saúde, Lélia, e muitos anos de vida!

\section{Referência}

DUARTE, Lélia Parreira. Exercícios de viver em palavra e cor. Belo Horizonte: Veredas \& Cenários, 2009. (Coleção Obras em Dobras Poiesis interlinguagens).

Para Ricardo Reis, óleo sobre tela, 110 x $70 \mathrm{~cm}$.

Extraída de Exercícios de viver em palavra e cor, p. 35.

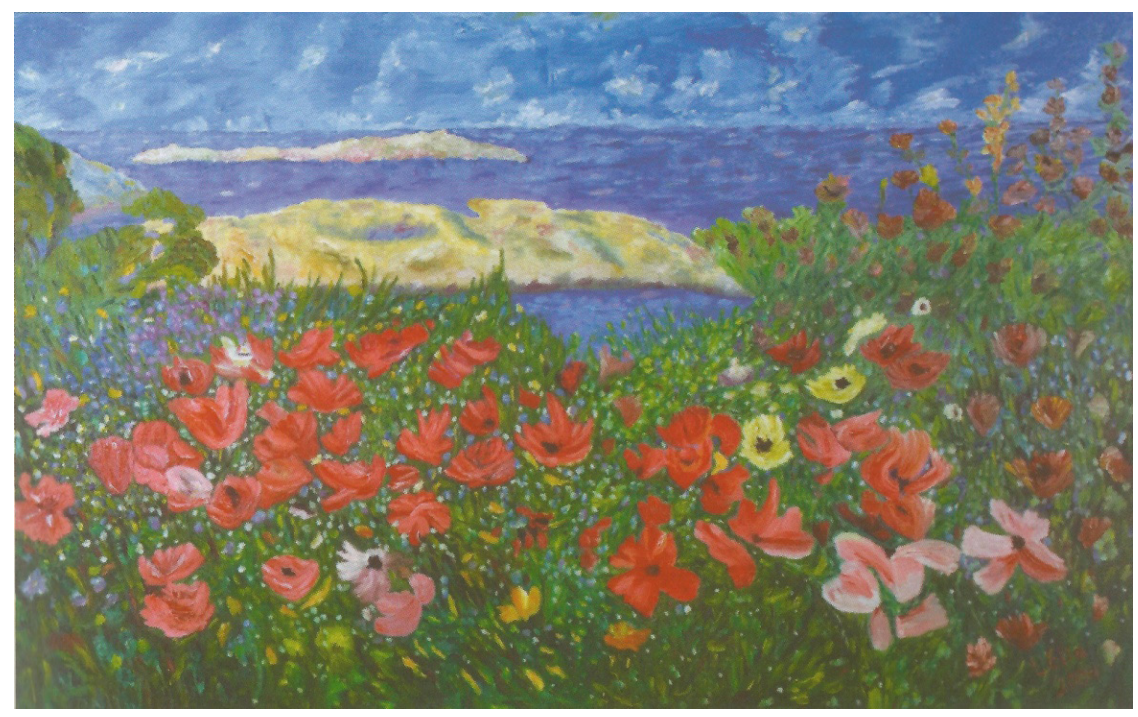


Chuva oblíqua, óleo sobre tela, 30 x $20 \mathrm{~cm}$.

Extraída de Exercícios de viver em palavra e cor, p. 45.

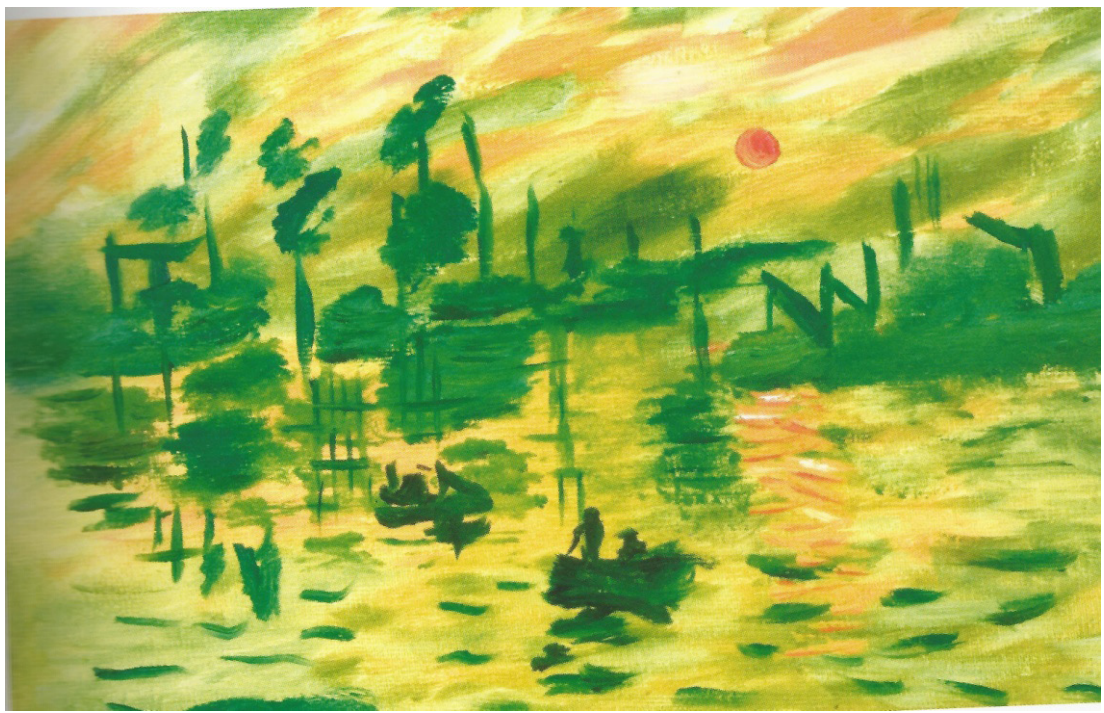

Enigmas, aquarela sobre papel, 9,5 x $15 \mathrm{~cm}$.

Extraída de Exercícios de viver em palavra e cor, p. 63.

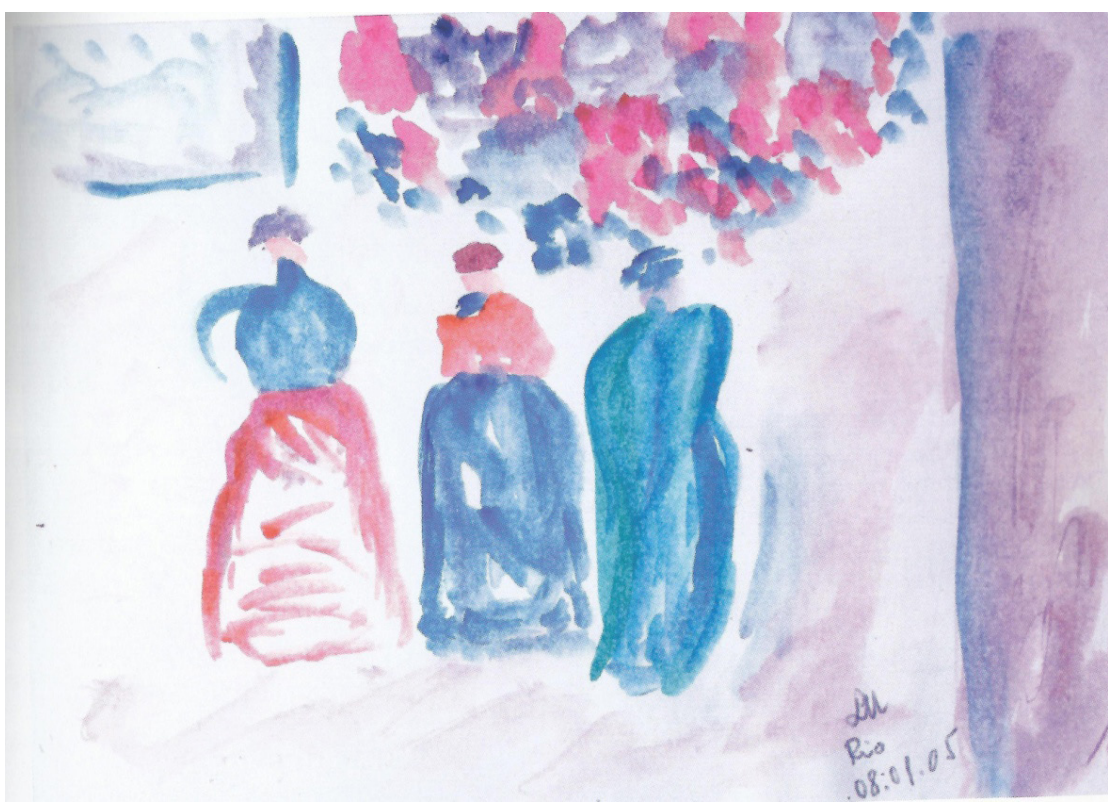

